\title{
O LIVRO ILUSTRADO DE LITERATURA INFANTIL NO BRASIL: HISTÓRIAS, CONCEPÇÕES E TRANSFORMAÇÕES
}

\section{THE PICTUREBOOK OF LITERATURE OF THE CHILDREN IN BRAZIL: STORIES, CONCEPTIONS AND TRANSFORMATIONS}

Andrea Rodrigues Dalcin ${ }^{1}$

\begin{abstract}
Resumo: Conhecer o percurso histórico do livro ilustrado nos permite analisar as transformações ocorridas quanto aos ideários desta literatura e a solidificação de seu acervo em diferentes décadas, movido por diferentes expectativas e voltado para leitores diversos em seu tempo e espaço. Analisar esse percurso no Brasil é condição para compreendermos esse nicho que produz um encontro entre imagem e palavra, que vê o ilustrador como escritor de imagens e que traz em seu projeto gráfico a descoberta da materialidade do livro enquanto objeto. Trabalharemos com a ideia de que o livro ilustrado traz uma maneira singular de diagramação e um encadeamento que se constrói na narrativa da história por meio da relação entre o texto, a imagem e o objeto livro diante dos sentidos produzidos pelo leitor. Este artigo está ancorado nos estudos de Hunt (2010), Linden (2011), Scott e Nikolajeva (2012), Oliveira (2008, 2013), Moraes, Hanning e Paraguassu (2012).
\end{abstract}

Palavras-chave: Livro Ilustrado; leitor; Literatura Infantil.

\begin{abstract}
Knowing the historical trajectory of the picturebook allows us to analyze the Transformations that have occurred during the ideas of this literature and the solidification of its heap in different decades, driven by different expectations and aimed at different readers in its time and space. Analyzing this way in Brazil is a condition for understanding this niche that produces a meeting between image and word, that sees the illustrator as a writer of images and that brings in his graphic project the finding of the materiality of the book as an object. We will work with the idea that the picturebook brings a unique way of diagramming and a series that is built in the narrative of story through the relationship between the text, the image and the book in front of the senses produced by the reader. This article is fixed in the studies of Hunt (2010), Linden (2011), Scott and Nikolajeva (2012), Oliveira (2008, 2013), Moraes, Hanning and Paraguassu (2012).
\end{abstract}

Keywords: Picturebook; reader; Literature of the Children.

Considerar que o livro ilustrado consiste antes de mais nada em uma combinação de textos e imagens não basta, contudo, para caracterizá-lo. [...] O livro ilustrado não é apenas texto e imagem, é texto e imagem no espaço desse estranho objeto que é o livro. A disposição das mensagens no suporte, o encadeamento do texto e das imagens, sua diagramação, sua localização também fazem sentido. (LINDEN, 2011, p. 86)

A definição de "livro ilustrado", discutida por pesquisadores, pelo mercado editorial e com a qual trabalharemos, se inscreve naquilo que Linden (2011) nos traz no excerto acima: a relação entre texto e imagem que se dá em um suporte, uma maneira singular de diagramação diante da disposição das mensagens, e um encadeamento que se constrói na narrativa da história por meio da relação entre o texto, a imagem e o objeto livro diante dos sentidos produzidos pelo leitor.

Entretanto, livro ilustrado, livro álbum, livro imagem, entre outros, são terminologias que vêm sendo pesquisadas e discutidas por muitos estudiosos, com definições e argumentos que ora os aproximam e ora os distanciam. Nessa direção, trazemos para este

\footnotetext{
${ }^{1}$ Universidade Estadual de Campinas, Campinas/SP.
} 
cenário o que Angela Lago afirma: "[...] o livro onde a imagem tem uma função narrativa, ele é um livro de imagem, independente de ter ou não ter texto e que isso é a visão comum fora do Brasil" (LAGO, 2012, p. 234). E acrescenta,

Chamam-se picturebooks ou álbuns os livros onde a imagem tem um viés narrativo, independente de estarem ou não acompanhados de palavras. Houve um mal-entendido, que acho que foi de um grupo pequeno no Brasil, de nomear como "livro de imagem" os livros sem texto. (LAGO, 2012, p. 234, grifos dos autores).

Moraes fortalece o discurso de Lago ao afirmar que:

No Brasil tem um complicador porque nos anos setenta, Juarez Machado fez dois livros, Domingo de manhã e Mistério da página 19, que foram chamados de livro-imagem ou livro de imagem, mas que são exclusivamente sem palavras. Isso fez ficar diferente o recorte no Brasil. Aqui, o picture book ou livro ilustrado com palavras é tratado como um livro com ilustrações. A função da imagem no picturebook é diferente da função da imagem no livro com ilustração. (MORAES, 2014, p. 28)

Nikolajeva e Scott, na tentativa de caracterizar os vários níveis de relação entre texto e imagem por meio de nomenclaturas constituídas em seu universo de pesquisa, assim trazem a discussão das definições sobre livro ilustrado:

[...] no Brasil essa nomenclatura ainda é controversa, optou-se pelas seguintes traduções: picturebook para "livro ilustrado", illustrated book, picture book e books with pictures para "livro com ilustração". Nessas três últimas denominações, a obra exemplificada não apresenta inter-relação explícita entre palavra e imagem. (NIKOLAJEVA E SCOTT, 2011, p. 13)

O livro ilustrado, enquanto forma de expressão que traz em seu bojo a interação entre texto, imagem e suporte, que pode conter inúmeras páginas duplas para marcar um tempo, uma sequência narrativa e promover a fruição da leitura na relação com diferentes linguagens, insere-se também no campo da literatura infantil cuja história foi escrita por vários estudos considerados precursores no campo da produção voltada para a criança, tais como Arroyo (2011), Lajolo e Zilberman (2007), Zilberman (2003), Coelho (2000 e 2010) e Cademartori $(2006)^{2}$. Estudos mais recentes também se debruçam sobre o gênero literatura infantil, trazendo contribuições como as de Maziero (2015) e Aleixo (2014).

No caso das ilustrações, destaca-se a pesquisa de Regina Yolanda Werneck sobre os ilustradores brasileiros, intitulada de O livro infantil e juvenil brasileiro: bibliografia de ilustradores (1977). Diante disso, nos encontramos no início dos estudos sobre a história da ilustração e do livro ilustrado compreendido, por pesquisadores, como uma história que ainda está por ser escrita, visto que suas origens parecem indefinidas (LINDEN, 2011, p. 11).

A produção sobre a história e crítica das ilustrações publicada nas duas últimas décadas, é, em grande parte, oriunda de pesquisadores estrangeiros, tais como Contos de Fadas: edição comentada e ilustrada, de Maria Tatar (2004); Era uma vez uma capa, de Alan Powers (2008); Crítica, Teoria e Literatura Infantil, de Peter Hunt (2010); Livro Ilustrado: palavras e imagens, de Maria Nikolajeva e Carole Scott (2011); Para ler o livro ilustrado, de Sophie Van der Linden (2011).

\footnotetext{
${ }^{2}$ Citando apenas alguns dos autores que compõem a quase totalidade das referências dos trabalhos de pesquisa realizados.
} 
No Brasil, as publicações teóricas sobre as ilustrações dos livros de literatura contaram com os seguintes títulos: Pelos jardins de Boboli: reflexões sobre a arte de ilustrar para crianças e jovens, de Rui de Oliveira (2008); O que é qualidade em ilustração no livro infantil e juvenil: com a palavra o ilustrador (2008), organizado por Ieda de Oliveira; Monteiro Lobato, livro a livro: obra infantil, organização de Marisa Lajolo e João Luís Ceccantini (2009); Traço e Prosa: entrevistas com ilustradores de livros infanto-juvenis, que traz um conjunto de entrevistas com ilustradores concedidas a Odilon Moraes, Rona Hanning e Maurício Paraguassu (2012).

\section{A ilustração do livro de literatura infantil: um olhar entre décadas}

De acordo com Oliveira (2008, p. 65-66), O patinho feio é considerado o primeiro livro infantil ilustrado e editado em quatro cores, no Brasil, destacando ainda que, na data de publicação, não constava na capa o nome do ilustrador Francisco Richter, aparecendo apenas o nome do autor, Hans C. Andersen e do coordenador da coleção, Arnaldo de Oliveira Barreto.

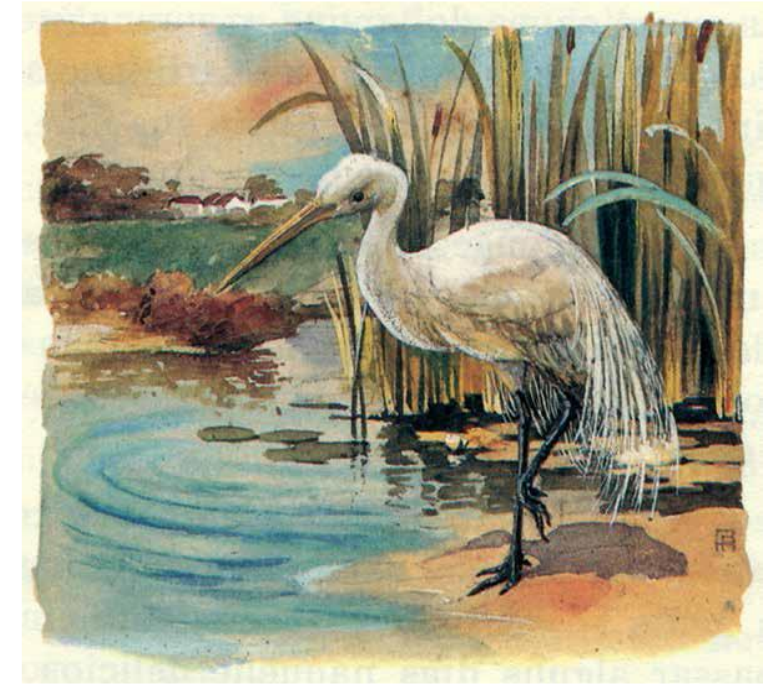

Figura 1: Ilustração do livro O Patinho Feio. Hans Christian Andersen. Weiszflog Irmãos Editores. $1915^{3}$.

Além disso, Oliveira (2008, p. 65-66) enfatiza que as ilustrações, “[...] já naquela época, tinham uma comunicação não-linear, própria da linguagem imagética" e Sandroni (2014) acrescenta que elas (as ilustrações) eram consideradas da mais alta qualidade, impressão e com acabamentos primorosos.

Em 1920, temos a publicação do livro A menina do narizinho arrebitado (1920), relançado no ano posterior como Narizinho Arrebitado (Segundo livro de leitura para uso das escolas primárias), além do livro $O$ Sacy, ambas de Monteiro Lobato (1921). Ilustrações de Voltolino, André Le Blanc, Belmonte, J. U. Campos e Manuel Victor Filho, entre outros, criaram, com seu talento, as figuras marcantes do Sítio do Pica-pau Amarelo.

No ano de 1936, o Ministério da Educação, por iniciativa do Ministro Gustavo Capanema, promoveu um concurso para livros de literatura infantil, abrangendo até o que se chamava então "álbum de estampas". Esse movimento, considerado inovador, possibilitou que dois grandes ilustradores fossem premiados: Santa Rosa (1909-1956), com O Circo, impresso na Bélgica, e Paulo Werneck (1907-1987) com a Lenda da Carnaubeira.

\footnotetext{
${ }^{3}$ Fonte: Serra, E. (Org.). A Arte de Ilustrar Livros para Crianças e Jovens no Brasil. Fundação Nacional do Livro Infantil e Juvenil. Rio de Janeiro: FNLIJ, 2013.
} 


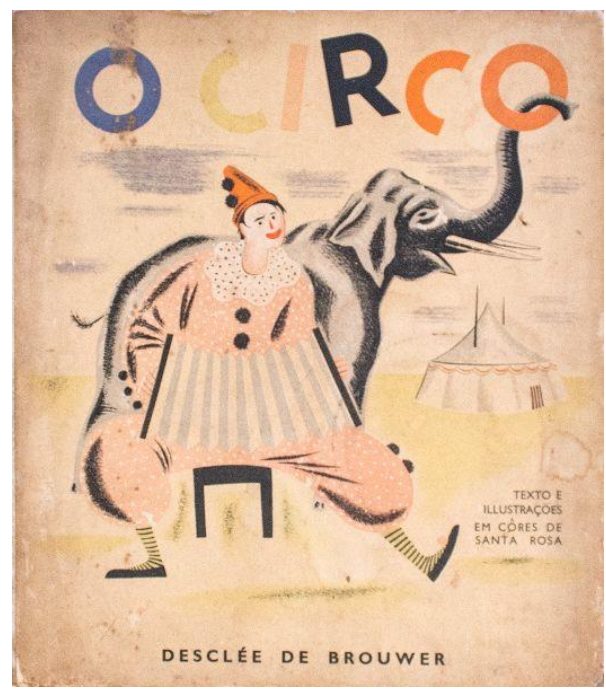

Figura 1: Capa do livro $O$ circo, ilustrações Santa Rosa

O texto que figura na capa do livro sugere destaque ao uso de ilustrações coloridas, ao marcar: "texto e ilustrações em cores de Santa Rosa". O livro é cartonado, com dimensões de 33 x 29,5 x 0,50. A seguir, temos as imagens do livro Lenda da Carnaubeira.

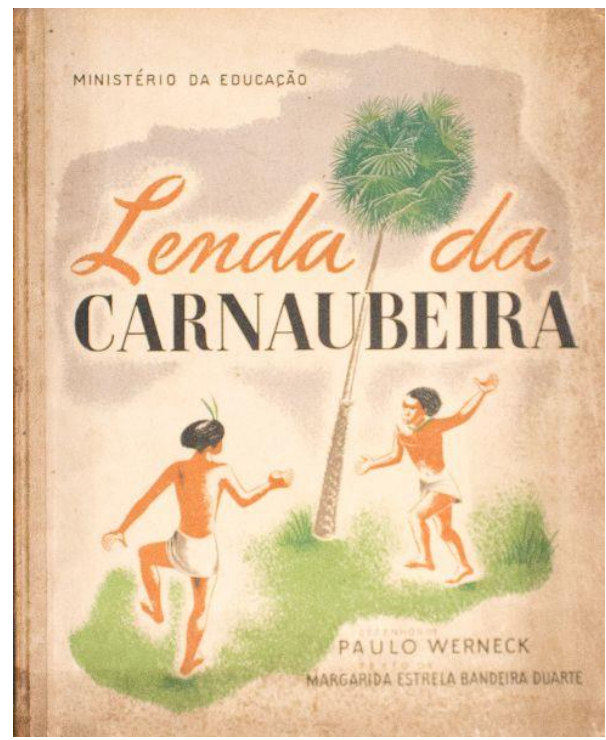

Figura 2: Capa do livro Lenda da Carnaubeira, de Paulo Werneck.

Na capa do livro destaca-se um aspecto importante: o nome do ilustrador aparece antes do nome da autora, Margarida Estrela Bandeira Duarte, o que parece indicar uma visão de que o ilustrador é tão importante quanto o autor do texto escrito. Todavia, Werneck está descrito como ilustrador, mas a capa traz a seguinte informação: "desenhos de Paulo Werneck", o que sugere uma falta de padronização para indicação do ilustrador.

Sobre a qualidade da obra, Manuel Bandeira assim se pronuncia no prefácio do livro:

No concurso aberto em julho de 1936 pela Comissão de Literatura Infantil do Ministério da Educação e da Saúde, esse livro obteve o terceiro prêmio na categoria A, isto é, álbuns de estampas para crianças menores de 7 anos. Fui voto vencido no julgamento atribuindo-lhe o segundo lugar, contra o voto dos colegas de comissão. Bastará lembrar esse fato para demonstrar o apreço em 
que tenho as admiráveis aquarelas com que Paulo Werneck ilustrou o gracioso texto da Sra. Margarida Estrela Bandeira Duarte. De fato as imagens do artista encantaram-me pela sua delicadeza, ingenuidade que me parece tão próxima da sensibilidade da primeira infância, pela singeleza da composição e do traçado. Em "Lenda da Carnaubeira" revela Paulo Werneck uma verdadeira vocação de ilustrador para a idade pré-escolar. Só depende agora dos nossos editores tirar-se partido dessa capacidade tão brilhantemente manifestada num concurso que tinha por fim principal descobrir vocações para um gênero ainda tão pobremente cultivado entre nós. (MANUEL BANDEIRA, prefácio, 1936)

A partir de 1969, as ilustrações de artistas brasileiros começam a ser selecionadas para concorrer a prêmios internacionais, como a Bienal de Ilustração de Bratislava, na Eslováquia, onde Eliardo França foi o ganhador da Menção Honrosa Maçã de Ouro (1975), pelas ilustrações da obra $O$ rei de quase-tudo ${ }^{4}$ que, por sua vez, também foi o primeiro livro a receber o prêmio Ofélia Fontes, o "Melhor para Criança", pela FNLIJ, em 1974. Este livro é considerado

Um dos mais importantes livros ilustrados da história da literatura infantil brasileira [...], marcou a estreia de Eliardo França no campo da autoria palavra \& imagem, após alguns anos unicamente como ilustrador de cores vibrantes e traços de sincera comunicação com as crianças. A obra havia conquistado Menção Honrosa no Concurso Paz na Terra, promovido pela FNLIJ em 1972 e, uma vez publicada, viajaria à Eslováquia onde conquistou Menção Honrosa na Bienal de Ilustração de Bratislava - BIB 1975 e, no ano seguinte, em um pouso na Grécia, receberia nova Menção Honrosa durante o Congresso do IBBY em Atenas; esteve presente na Feira do Livro de Frankfurt, na Alemanha, em 1978; veio-lhe o reconhecimento da Unesco, em 1979, primeiro lugar na categoria "Livro para um Mundo Melhor", além de festejado com vários selos de "Altamente Recomendável" [...]. (SAGAE, Dobras da Leitura, 2012, s/p). ${ }^{5}$

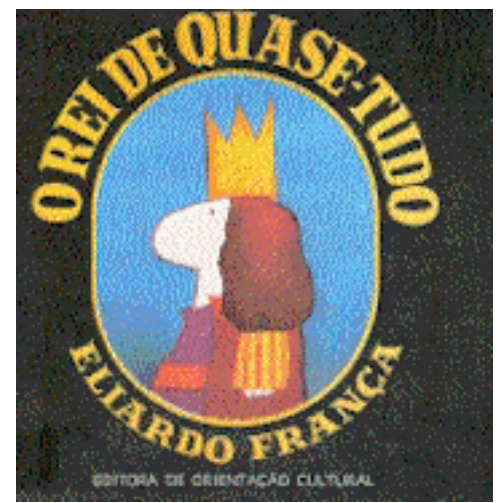

Figura 4: Capa do livro $O$ rei de quase-tudo, por Eliardo França $(1971)^{6}$

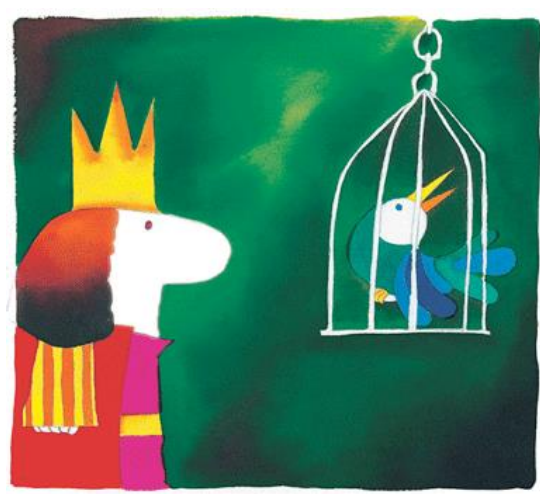

Figura 3: Página do livro $O$ rei de quase-tudo, por Eliardo França $(1971)^{7}$

\footnotetext{
${ }^{4}$ Após 45 anos da primeira publicação da obra $O$ rei de quase-tudo, uma nova versão lhe é conferida em outro suporte. A plataforma $\mathrm{iPad}$, criada pelo filho do autor, Lucas França, traz 13 páginas interativas e animadas, em quatro diferentes línguas (inglês, português, espanhol e francês), além de ganhar uma trilha sonora composta especialmente para a $a p p$. ${ }^{5}$ SAGAE, P. O. Quase tudo de volta ao rei (2012). Disponível em: http://dobrasdaleitura.blogspot.com.br/2012/05/quasetudo-de-volta-ao-rei.html. Acesso em 19/01/2017.

${ }^{6}$ Capa e página do livro O rei de quase-tudo. Disponível em: http://www.fnlij.org.br/site/pnbe-1999/item/258-orei-de-quase-tudo.html. Acesso em: 20/01/2017.

${ }^{7}$ Capa e página do livro O rei de quase-tudo. Disponível em: http://www.fnlij.org.br/site/pnbe-1999/item/258-orei-de-quase-tudo.html. Acesso em: 20/01/2017.
} 
O traço e as cores vibrantes da aquarela líquida, muito comum nos trabalhos dos anos 1979, foram produzidos por Eliardo França há 40 anos e sugere um ilustrador com domínio criativo, que discute nessa obra a relação entre a literatura infantil, o poder, a repressão e a censura que definiam o sistema e a ordem da vida brasileira na época. Esse movimento não foi feito apenas pelo texto verbal, mas pelas imagens sutis e delicadas, as que nos gestos e nas expressões do rei mostram o autoritarismo.

De acordo com Oliveira (2013, p. 25), foi a partir dos anos 1970 e 1980 que, pela primeira vez, a profissionalização e o surgimento de ilustradores, dedicados exclusivamente à ilustração de livros passou a acontecer. E ainda complementa,

Vale lembrar que o Brasil possui atualmente a $8^{\mathrm{a}}$ indústria de livros do mundo. Ante a grande demanda de designers, capistas, diretores de arte e ilustradores, não há mais espaço para o diletantismo, tampouco o exercício do ofício de ilustrar como uma atividade adicional e ocasional. Não temos dúvida de que a história e o desenvolvimento da arte de ilustrar, no que se refere ao aspecto técnico, formal e conceitual, estiveram sempre associados às questões tecnológicas e industriais. No Brasil não foi diferente. Não se trata de uma visão automática ou fatalista, é simplesmente uma constatação. A arte de ilustrar livros passou pela xilogravura, gravura em metal, litografia, cromolitografia, offset e atualmente impressão digital, portanto, várias etapas ligadas à tecnologia de época. (OLIVEIRA, 2013, p. 25)

Regina Yolanda organizou, em 1972, a exposição intitulada Retrospectiva da ilustração na Literatura Brasileira para Crianças, na sede da Caixa Econômica Federal, no centro do Rio de Janeiro, coordenada pela FNLIJ, ações essas que marcam um novo estatuto para a ilustração do livro de literatura infantil no Brasil.

Outro traço da modernidade presente nessa época se refere à ênfase dada aos aspectos gráficos, não mais vistos como subsidiários ao texto, mas como elemento autônomo. Obras como O caneco de prata (1971), de João Carlos Marinho e Chapeuzinho Amarelo (1979), de Chico Buarque, mas principalmente através das produções Flicts (1969), de Ziraldo; Domingo de manhã e Ida e volta (1976), de Juarez Machado; O ponto (1978), de Ciça e Zélio; Depois que todo mundo dormiu (1979), de Eduardo Piochi e $O$ menino maluquinho (1980), de Ziraldo, que os livros de literatura infantil convocam as ilustrações e seu visual como a essência do livro e não mais como um reforço ao texto verbal.

Sobre Flicts, Roger Mello diz que esta obra

[...] é genial [...]. O Ziraldo atingiu todas as dimensões narrativas do abstrato quando fez o Flicts! Um livro infantil revolucionário e mostra que o artista pode conseguir ser tão experimental como a criança! O Ziraldo é um divisor de águas aqui e no mundo. (MELLO, 2012, p. 205-206)

Nessa direção, Flicts é uma obra que rompe com a estética predominante para levar às crianças o mais moderno e inovador do desenho gráfico, que parece desafiar o leitor diante da abstração e da livre apreciação.

Tal inovação foi pensada, de acordo com Lima (2009, p. 33), em uma década na qual os livros passam a receber tratamento de produto voltado ao público infantil, sendo oferecida a possibilidade de uma leitura ao leitor iniciante através de livros com supremacia de narrativa visual, contendo pequenos textos de fácil compreensão, o que parece reafirmar a ideia de que 
tais livros se constituíam como produtos para leitores que ainda "não eram fluentes", associando assim leitura de imagens com textos fáceis para crianças não alfabetizadas.

Eliardo França, com as ilustrações de A coleção Gato e Rato, publicadas em 1978, totalizando 35 (trinta e cinco) títulos, produz um jogo lúdico entre ideias e construções linguísticas, compondo cenas que ora se apresentam como engraçadas e ora se apresentam como tensas. São narradas por meio de textos curtos, diálogos rápidos, frases bem construídas, numa constante bricolagem com as ilustrações bem coloridas, limpas e fluidas envoltas por traçados simples, que criam um ritmo ágil e estimulante para o leitor, possibilitando a aceitação pelos pequenos leitores.

Livro fabricado para um público definido - crianças na fase de pré-alfabetização - esta coleção foi alvo de muitos prêmios: prêmio Ofélia Fontes "O melhor para criança" (1978), pela FNLIJ, prêmio Jabuti/Prêmio para Coleções (1978), Menção Honrosa para o livro O rabo do gato, pela Muestra Internacional de Publicaciones Infantiles e Juveniles/Espanha (1979), prêmio Bienal/Noroeste de Literatura Infantil e Juvenil//lustrador (1982), Associação Paulista Dos Críticos de Arte/Prêmio Ilustração (1986) e Selo Altamente Recomendado/Imagem (1986). Com essas premiações, notamos a importância do conjunto da obra ao longo de quase uma década após os primeiros lançamentos, o que sugere qualidade e conexão com os ideários e preocupações da nação: um país com crianças alfabetizadas, em que a ilustração ganha status e qualifica a obra.

Apesar de pensada para este público definido, o que sugere uma determinada compreensão de leitura, Eliardo França esclarece que "[...] a criança não lê somente a palavra escrita; a imagem tem o mesmo peso da palavra" (FRANÇA, 2012, p. 22). Imbuídos desse pensamento, autores e ilustradores alteram suas maneiras de fazer e pensar o livro, pois "Nos anos 1960, na Europa, e nos anos 1970 no Brasil, chega um movimento da ilustração não mais de interpretar, mas de acompanhar a narrativa, em que já não é mais a qualidade do desenho que está sendo julgada, mas o quanto ele fala (MORAES, 2014, p. 27).

Com esses ideários sendo estabelecidos, no decênio de 1980, outras formas de pensar o livro, bem como novos autores e ilustradores, passam a figurar no nicho que envolve a literatura infantil. É o período em que Rui de Oliveira traz a experiência vivida no Instituto Superior de Artes Industriais, na Hungria, para o livro infantil. Angela Lago e Eva Furnari se destacam com suas narrativas visuais consideradas bem humoradas, perpassadas por um fino e delicado tratamento gráfico. Jô de Oliveira arrisca-se e traz para o livro infantil a influência da arte popular através da xilogravura dos tão conhecidos cordéis, e Ricardo Azevedo, com um traçado limpo e, principalmente, expressivo, narra histórias do folclore brasileiro de forma brilhante. Destacam-se também os nomes de Walter Ono, Ciça Fitipaldi, Claudio Martins, Miadaira, Alcy Linares, Alice Góes, Elvira Vigna, Gê Orthof, Tato Orthof, Luís Camargo, Naomi Koruba, entre outros que figuram nesse nicho, por constituir um período de firmação do trabalho do ilustrador.

Em 1987, houve mais uma ação para divulgar a arte de ilustrar livros, com a exposição intitulada Mostra de Ilustradores para Crianças, e em 1989, a convite de Arnaldo Niskier, a FNLIJ organizou o catálogo Ilustradores Brasileiros de Literatura Infantil e Juvenil, consolidando a importância dos ilustradores.

$\mathrm{Na}$ década de 1990, novas mudanças passaram a constituir o tratamento dado ao visual do livro infantil brasileiro. Nessa direção, encontramos uma nova geração de ilustradores designers, que se incumbiram da elaboração geral do projeto gráfico do livro e, junto a isso, surgiram novas tecnologias de produção e impressão da imagem que sofisticaram e elevaram a qualidade do produto final.

Neste momento, uma reflexão acerca de nossas raízes culturais é o mote das produções e se reflete nas paletas de cores e na organização do espaço plástico do livro. Destacam-se, neste período, os trabalhos de Roger Mello, Mariana Massarani, Graça Lima, Ivan Zigg, Guto Lins, 
Elizabeth Teixeira, Helena Alexandrino, Nelson Cruz, Marilda Castanha, Luís Maia, Odilon Moraes, Renato Alarcão.

Esta década pode ser considerada como o ponto alto da participação dos ilustradores brasileiros no cenário internacional: Feira de Frankfurt (1994), Feira do Livro Infantil de Bolonha, cujo país homenageado foi o Brasil (1995) e possibilitou trazer ao país a exposição Jardim Secreto, comemorativa dos 30 anos da Mostra de Ilustração, que compreendeu os originais dos trinta ilustradores premiados (1996).

Marcado por um número cada vez maior de profissionais ilustradores, o início do século XXI desponta com tecnologias que geram novas linguagens e novas possibilidades de trabalho junto ao objeto livro, devido até à criação vertiginosa dos cursos com formação específica para designer. André Neves, Andrés Sandoval, Cristina Biazeto, Fernando Vilela, Salmo Dansa, Suppa, Rosinha Campos e Ana Terra são nomes que vêm marcando este novo panorama gráfico na produção de livros de literatura infantil.

Segundo Oliveira, desde o final dos anos 1980 e, principalmente ao longo dos anos 1990, operou-se em nosso país, bem como em todo o mundo, uma profunda transformação em toda a história da indústria gráfica: "a impressão e a captura de imagens por processos digitais" (OLIVEIRA, 2013, p. 25).

O registro da imagem por scanner de alta definição, a utilização dos sempre renovados softwares na criação gráfica, e, naturalmente, na criação de ilustrações, imagens diversas, projetos editoriais e, finalmente, o transporte direto desta imagem e tipografia para a chapa de impressão, eliminando o fotolito, todos estes aspectos representam uma revolução conceitual e industrial sem precedentes. (OLIVEIRA, 2013, p. 25)

Nessa direção, ainda segundo Oliveira (2013), a ilustração de livros infantis e juvenis pelo processo digital, bem como a própria arte digital exigem novas reflexões estéticas. E, acrescenta:

Embora ainda no seu início, e diante de um futuro absolutamente imprevisível, mesmo assim já podemos anunciar alguns impasses quanto a essa nova realidade, a começar pela própria essência do aprendizado do ofício do ilustrador, onde a ausência da tradicional habilidade manual para desenhar e pintar não representa mais tanto empecilhos para um bom criador digital. Frequentemente vemos a utilização por parte dos ilustradores - e isto é um fenômeno internacional - de processos artesanais acoplados a processos digitais em seu trabalho. Portanto, a arte digital não é a negação do passado; ela é a sua revitalização em novos estágios da criação. A ilustração digital não deve ser interpretada como uma ruptura com a tradição, o que seria, em si, uma leitura reacionária e conservadora. A colocação que se faz também é eterna: a questão não está localizada na linguagem, digital ou gráficopictórico-artesanal, e sim, no talento, na criatividade, no discernimento e cultura do artista que se dispõe a ilustrar para o mais precioso, crítico, e fiel público que existe: a criança e o jovem. (OLIVEIRA, 2013, p. 26)

Independente do período histórico nos parece que as imagens possuem vida real que ultrapassa gerações, perpetuando-se individual e coletivamente em torno do imaginário e da maneira de pensar tanto pessoal como nacional, temporal e atemporal. Nessa direção, trazemos uma frase de Oliveira $(2013$, p. 22) que completa com toda reverência uma frase proferida por Lobato: “[...] um país se forma com homens, livros e imagens. Esta última, no sentido mais amplo da palavra". 
Na história da ilustração, o recorte aqui apresentado trata o livro ilustrado como aquele que traz ilustrações de qualidade em que elas (as ilustrações), sempre estiveram presentes acompanhando o texto verbal. No entanto, neste cenário, o livro ilustrado se forma, se transforma e marca um tipo de obra que possui uma visão específica.

\section{O livro ilustrado e as discussões contemporâneas}

[...] com o desenho se escreve. Isso é a base de tudo. Um livro-imagem é um livro de imagens sem história? Não, é um livro no qual a história está escrita com desenhos, é como um hieróglifo; essa é a base para o gênero literário onde a imagem escreve. Você pode então ter um livro-imagem só com imagem e um livro-imagem também com texto, em que os dois escrevem. (MORAES, 2014, p. 28)

Talvez desde os anos 1970 exista o livro ilustrado no Brasil. Quando falamos em livro ilustrado, pensamos em uma obra cuja ilustração narra e escreve um fato ao mesmo tempo em que o texto conta outro ou o mesmo de forma distinta. Texto e ilustração podem se opor, se complementar ou se compor diante da imensa variedade da quantidade de ilustrações e das maneiras singulares que compõem cada página do livro ilustrado. Ao notar que a imagem não "traduz" aquilo que está escrito pela palavra, a atenção parece alterar a forma de ler: o olhar não mais desliza linearmente por entre as linhas, não segue um fluxo contínuo da esquerda para a direita, ele parece saltar entre a mesma página ou entre diferentes páginas, num movimento de ida e volta do olhar, de descer e subir ou vice-versa pelos protocolos de leitura inscritos na página, de comparar informações entre ilustração e palavra, de buscar pistas, estabelecer conexões, levantar hipóteses e, constantemente, revisá-las, sempre no jogo entre texto e imagem.

Na perspectiva assumida por este trabalho, existe uma prática cultural de leitura que é ensinada/aprendida, permitindo que o leitor se desafie em suas conexões que transitam do esperado ao inesperado, da fantasia à realidade, do literal ao metafórico diante de, por exemplo, narrativas paralelas, como no livro Hora de sair da banheira, Shirley! de John Burningham.

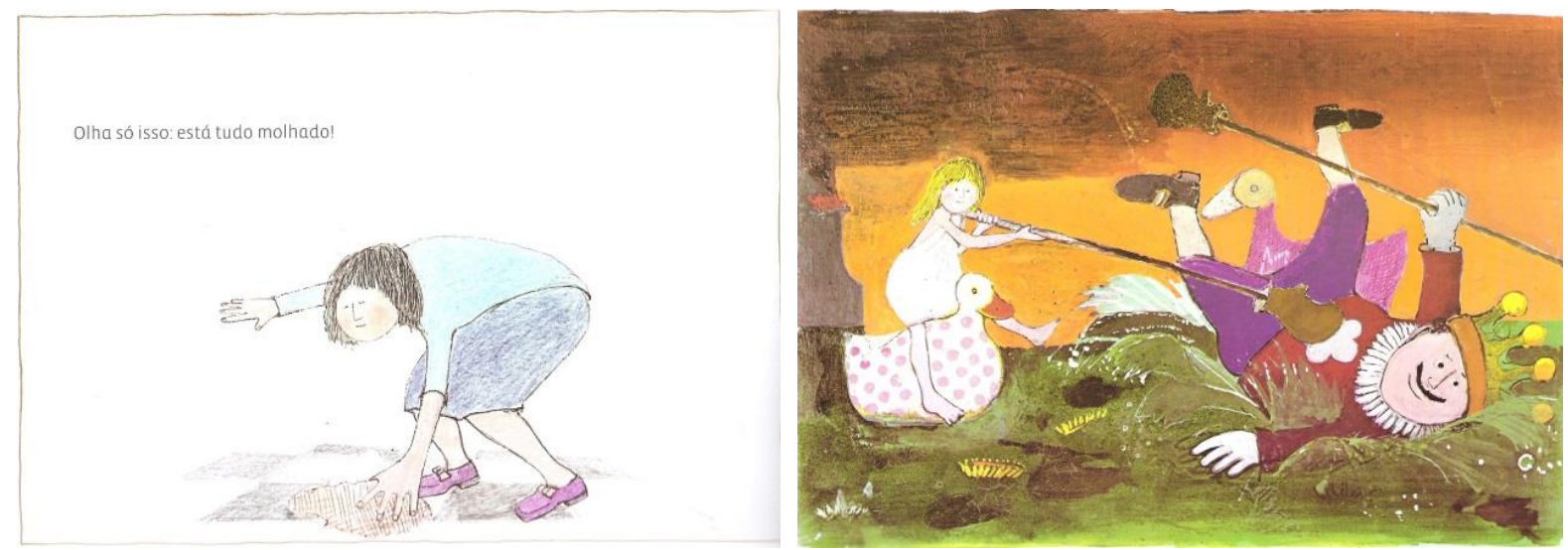

Figura 64: Páginas do livro Hora de sair da banheira, Shirley! de John Burningham, 2011.

De um lado, encontramos a mãe ${ }^{8}$, que em sua perspectiva observa as peripécias de sua filha no banheiro (Figura 6): é a roupa suja e a água espalhada pelo chão, e a mãe limpando, arrumando, enxugando. A visão do adulto é entremeada a uma página branca, praticamente sem

\footnotetext{
${ }^{8}$ Essa história possui duas personagens: a mãe e sua filha. Enquanto a mãe reclama das roupas que a filha deixou no chão do banheiro e do sabonete que ficou na água, Shirley transforma sua banheira num reino encantado, com príncipes cavaleiros e castelos.
} 
cores. Já a página que destaca a imaginação da criança durante o banho possui cores, movimentos e diferentes ações. Nesse ínterim, destacamos outros dois elementos desse tipo de obra: o previsível e o imprevisível, a depender do leitor (adulto e criança) de uma obra fabricada por uma relação de interdependência entre imagens e palavras.

Considerando que a ilustração também é escrita e que essa escrita parece marcar uma das características do livro ilustrado, continuemos nossas considerações com o livro Lá e aqui ${ }^{9}$, de Carolina Moreyra e Odilon Moraes, publicado em 2015. Nas palavras de Eva Furnari, no livro ilustrado, o desenho enquanto linguagem, desde que não seja estereotipado, "[...] tem o incrível potencial de narrar, exprimir, emocionar e até alterar um estado de espírito" (FURNARI, 2012, p. 49), como vemos, por exemplo, em Lá e aqui (Figuras 7 e 8), com suas cores, sequência narrativa, página dupla e uma emoção sem palavras.

A Figura 7 mostra a alegria de uma família no jardim de sua casa, uma casa em que toda família poderia viver feliz. Os cachorros, os peixes, um lago, flores coloridas, sapos, pássaros e uma árvore. A felicidade da família está estampada na cena aqui apresentada.

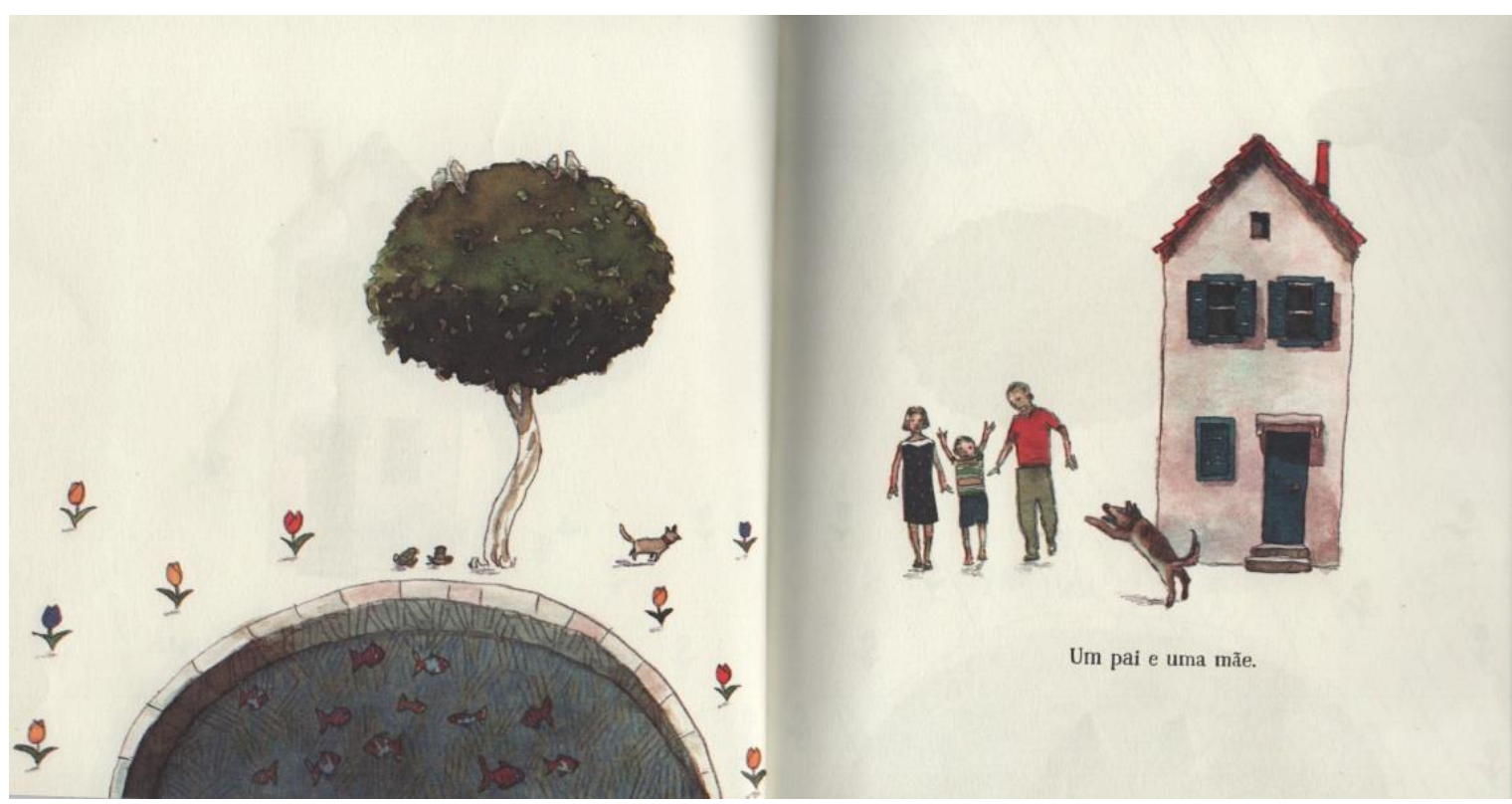

Figura 75: Página dupla do livro Lá e aqui, de Carolina Moreyra e Odilon Moraes, 2015, 1ª edição.

Mas, um dia tudo mudou e, como em uma tempestade, a casa se afogou e tornou-se triste e vazia. A página dupla na Figura 8 mostra o poder que a ilustração possui em narrar emoções na qual uma família feliz recebe o impacto de uma separação e, com isso, os olhos da mãe encheram-se de lágrimas traduzidas nos peixes que viviam no jardim. A cor da água, os pingos de chuva, as nuvens cinzentas, enfim, a casa já não é mais a mesma.

\footnotetext{
${ }^{9}$ A obra recebeu o Premio FNLIJ - O melhor para criança 2016, indicado entre os 30 Melhores Livros da Revista Crescer e selecionado para constituir o acervo de literatura infantil da Internationale Jugendbibliothek IJB de Munique/Alemanha. Além disso, conquistou o $2^{\circ}$ lugar da categoria Livro Infantil do $58^{\circ}$ Premio Jabuti, concedido pela CBL. A escritora Carolina Moreyra aborda com sutileza e delicadeza um assunto complexo: a separação dos pais. Com traços simples e característicos do ilustrador Odilon Moraes, imagens e textos se fundem para narrar, aos olhos de uma criança, a separação que pode ser vivida de maneira positiva sem que o sentimento inicial seja pormenorizado.
} 


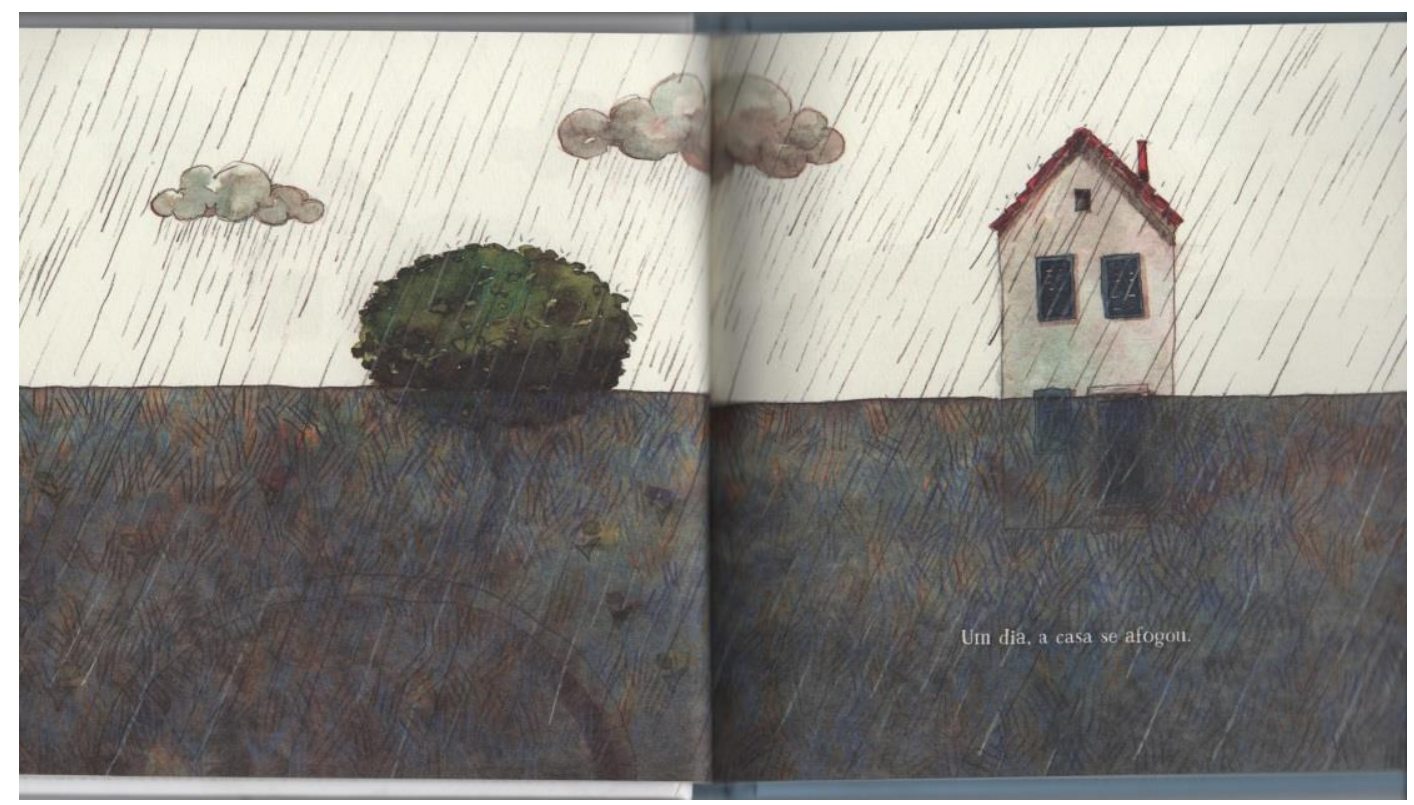

Figura 6: Página dupla do livro Lá e aqui, de Carolina Moreyra e Odilon Moraes, 2015, $1^{\text {a }}$ edição.

O livro ilustrado não só lida com cores/traços, não se define pela preocupação do ilustrador em dar a imagem, o estatuto antes exclusivo ao texto; ele também se faz/configura no uso das páginas duplas em que a ilustração se esparrama, se complementa, se contrapõe. A imagem não cabe em uma única página, como vemos nas Figuras 7 e 8 do livro Lá e aqui. A importância dada ao lugar que a imagem ocupa na página para criar um efeito "na virada da página" é um recurso próprio da contemporaneidade na história do livro ilustrado.

Segundo ilustradores, os livros ilustrados ousam e inovam tanto em relação ao conteúdo quanto aos aspectos que envolvem a materialidade do objeto livro, que extrapola a própria ilustração criada por eles. Para Reyes (2012), a especificidade do livro ilustrado é marcada pela conversa que o ilustrador intenciona estabelecer entre texto e ilustração alcançando talvez:

[...] a marca da beleza - ou o nascimento da arte - o que se vislumbra alcançar nos olhos das crianças, enquanto olham fixamente para os olhos amarelos dos monstros, para decifrar-se por dentro. Essa experiência poética de descobrir que habitamos duas margens, e que o lugar conhecido não está tão longe do outro - o imaginário - como cremos, e que é possível navegar em um barco "onde estão as coisas selvagens" (título original em inglês), e regressar à casa, no momento exato de jantar, é o que o transformou em um livro de formação para a psique infantil. (REYES, 2012, s/p)

Com a preocupação de fazer um panorama do livro ilustrado, Kátia Canton, Odilon Moraes e Fernando Vilela realizaram uma exposição em $2011^{10}$. Para os organizadores da exposição o livro ilustrado tem sido considerado uma das experiências mais inovadoras da literatura infantojuvenil das últimas décadas, ganhando espaço cada vez maior nas prateleiras das livrarias, entre a crítica especializada de arte e literatura e entre os leitores, porém não há menção à escola.

\footnotetext{
${ }^{10}$ Intitulada de Linhas da história - Um panorama do livro ilustrado no Brasil, a exposição partiu exatamente da seguinte proposição: "é possível fazer um panorama do livro ilustrado em uma exposição?”. Tal interrogação foi realizada por Kátia Canton, Odilon Moraes e Fernando Vilela, após serem convidados pelo SESC para compor, junto a ele, a curadoria da mostra pensada pelo Núcleo de Imagens e Palavras do SESC Belenzinho, São Paulo.
} 
De acordo com Vilela $(2011, \mathrm{~s} / \mathrm{p})^{11}$, a primeira decisão tomada foi planejar uma exposição em que o olhar estaria direcionado para os livros ilustrados e não para as ilustrações. Nessa direção, o ponto de partida foi realizar a seleção dos livros mais representativos para compor o espaço da exposição desde a década de 1970 até o ano de 2011.
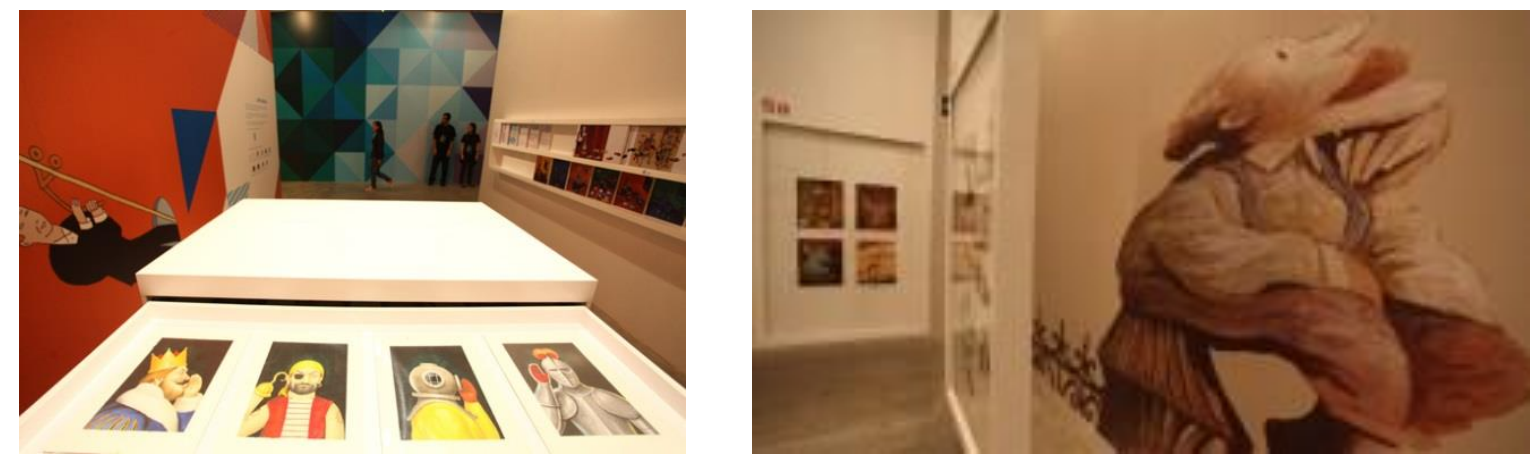

Figura 9: Imagens selecionadas de livros ilustrados para compor a exposição da história - Um panorama do livro ilustrado no Brasil (2011)

Mais de cem ilustradores foram pesquisados, porém por questões de espaço e orçamento, a exposição precisou ser limitada a quarenta $\operatorname{artistas~}^{12}$, cujas obras se destacaram a partir de temas, linguagens e gêneros, diversidade e criatividade no processo de criação. Enquanto curador da exposição, Moraes destaca que as imagens escrevem ideias, narram histórias repletas de sutilezas, desafios, buscas, diferentes caminhos que o leitor - adulto ou criança - parece descobrir ao longo da leitura.

A organização da exposição promoveu um mapeamento inédito da produção em ilustração no Brasil, contando ainda com discussões sobre as tendências expressivas dessa linguagem em 58 livros apresentados de 1969 a 2010. Os trabalhos expostos transitam entre as técnicas consideradas mais tradicionais como o desenho e a pintura, as inúmeras possibilidades de experimentação gráfica, colagem, fotografia, bem como influências da produção artesanal, bordados, rendas e cordel.

Em 2017, uma nova exposição foi realizada no Sesc Santo André e foi intitulada de Linhas de Histórias: o livro ilustrado em 7 autores cuja proposição foi a de investigar o processo de criação de livros ilustrados de sete autores: Andres Sandoval, Ângela Lago, Eva Furnari, Javier Zabala, Nelson Cruz, Renato Moriconi e Roger Mello mostrando inspirações e formas de criação singulares de cada um dos artistas. A exposição teve a curadoria de Fernando Vilela, Odilon Moraes e Stela Barbieri e marca a história do livro ilustrado, assim como a realizada em 2011.

Exposições que se inscrevem na história do livro ilustrado no Brasil e trazem as marcas do processo de criação e produção do livro ilustrado, bem como a busca por mostrar ao leitor, como nos traz Hunt (2010, p. 236), que “[...] não há nenhum sentido no qual as imagens possam 'simplesmente' ilustrar o que as palavras dizem; elas devem interpretá-las [...]'. Além disso, para Nodelman (1998, p. viii), "[...] os livros ilustrados possuem ritmos singulares, convenções

\footnotetext{
${ }^{11}$ Entrevista cedida à exposição Linhas da história - Um panorama do livro ilustrado no Brasil (2011).

${ }^{12}$ Artistas que participaram: Alcy Linares, Angela Lago, André Neves, Andrés Sandoval, Cárcamo, Ciça Fitipaldi, Cynthia Cruttenden, Dave Santana e Maurício Paraguassu, Daniel Bueno, Daneil Kondo, Demóstenes Vargas e Família Dummont, Eliardo França, Elisabeth Teixeira, Eva Furnari, Gilles Eduard, Graça Lima, Helena Alexandrino, Ionit Zilbermann, Ivan Zigg, Jean Claude Alphen, Juarez Machado, Laura Teixeira, Luiz Zerbini, Marcelo Cipis, Marcelo Xavier, Maria Eugênia, Marilda Castanha, Mariana Massarani, Maurício Negro, Nelson Cruz, Orlando, Pedro Rafael, Renato Moriconi, Ricardo Azevedo, Rosinha Campos, Roger Mello, Rui de Oliveira, Salmo Dansa e Suppa. Disponível em: http://marandubinha.com.br/exposicao-linhas-da-historia-um-panoramado-livro-ilustrado-no-brasil/. Acesso em: 03/06/2017.
} 
singulares de forma e estrutura, um corpo singular de técnicas narrativas", o que talvez tenha sido objetivo de cada núcleo evidenciar em relação à singularidade das obras expostas.

Todavia, no movimento de um livro pensado e fabricado por meio de uma bricolagem entre texto, ilustração e suporte para que se constituam os sentidos da leitura, no polo da recepção encontramos o leitor na prática de ler esse tipo de obra, na multiplicidade que pode se fazer presente nesse ato.

\section{Referências}

ALEIXO, Eliette Aparecida. Palavras e imagens que tecem histórias: ilustradores/escritores e a criação literária para a infância. 2014. Tese (Doutorado em Educação). Universidade Federal de Minas Gerais.

ARROYO, Leonardo. Literatura Infantil Brasileira. 3. ed. São Paulo: Editora Unesp, 2011.

BURNINGHAM, John. Hora de sair da banheira, Shirley! 1. ed. Tradução: Claudio Alves Marcondes. São Paulo: Cosac Naify, 2011.

CADEMARTORI, Ligia. O que é literatura infantil. Primeira reimpressão. 7. ed. São Paulo: Brasiliense, 2006.

COELHO, Nelly Novaes. Literatura infantil: teoria, análise, didática. São Paulo: Moderna, 2000.

COELHO, Nelly Novaes. Panorama histórico da literatura infantil/juvenil: das origens indoeuropeias ao Brasil contemporâneo. 5. ed. Barueri, SP: Manole, 2010.

FRANÇA, Eliardo. Entrevista. In: MORAES, Odilon; HANNING, Rona; PARAGUASSU, Maurício. Traço e prosa: entrevistas com ilustradores de livros infantojuvenis. São Paulo: Cosac Naify, 2012.

HUNT, Peter. Crítica, teoria e literatura infantil. Tradução Cid Knipel. São Paulo: Cosac Naify, 2010.

LAGO, Angela. Entrevista. In: MORAES, Odilon; HANNING, Rona; PARAGUASSU, Maurício. Traço e prosa: entrevistas com ilustradores de livros infantojuvenis. São Paulo: Cosac Naify, 2012.

LAJOLO, Marisa; CECCANTINI, João Luís (Org.). Monteiro Lobato, livro a livro: Obra infantil. 1. reimp. São Paulo: Editora UNESP; Imprensa Oficial do Estado de São Paulo, 2009.

LAJOLO, Marisa; ZILBERMAN, Regina. Literatura Infantil Brasileira: Histórias e Histórias. 6. ed. São Paulo: Ática, 2007.

LIMA, Graça. A ilustração no Brasil. In: Secretaria de Educação à Distância/Ministério da Educação. A arte de ilustrar livros para crianças e jovens. TV Escola: Salto para o futuro, p. 29-44, ano XIX, n. 7, junho/2009. 
LINDEN, Sophie Van der. Para ler o livro ilustrado. Tradução Dorothée de Bruchard. São Paulo: Cosac Naify, 2011.

MAZIERO, Maria das Dores Soares. Arnaldo de Oliveira Barreto e a Biblioteca Melhoramentos (1915-1925): histórias de ternura para mãos pequeninas. 2015. Tese (Doutorado em Educação). Universidade Estadual de Campinas.

MELLO, Roger. Entrevista. In: MORAES, Odilon; HANNING, Rona; PARAGUASSU, Maurício. Traço e prosa: entrevistas com ilustradores de livros infantojuvenis. São Paulo: Cosac Naify, 2012.

MORAES, Fabiana Mariano. As ilustrações de Walter Crane no conto Chapeuzinho Vermelho do século xix: a força comunicativa exercida pelo desenho na narrativa. Salvador BA: UCSal, v. 6, n. 3, out. 2014, p. 352-365. Disponível em: http://aninter.com.br/anais\%20coninter\%203/gt\%2006/23.\%20moraes.pdf. Acesso em: 17/03/2017.

MORAES, Odilon. O livro ilustrado: palavra, imagem e objeto na visão de Odilon Moraes. Literartes, n. 3, p. 26-32, 2014. Disponível em: http://www.revistas.usp.br/literartes/article/view/89198/92110. Acesso em: 17/01/2017.

MORAES, Odilon; HANNING, Rona; PARAGUASSU, Maurício. Traço e prosa: entrevistas com ilustradores de livros infantojuvenis. São Paulo: Cosac Naify, 2012.

MOREYRA, Carolina. Lá e Aqui. Rio de Janeiro: Pequena Zahar, 2015.

NIKOLAJEVA, Maria; SCOTT, Carole. Livro ilustrado: palavras e imagens. Tradução Cid Knipel. São Paulo: Cosac Naify, 2011.

NODELMAN, Perry. Words about images: the narrative art of children's picture books. Athens: University of Georgia Press, 1998.

OLIVEIRA, Rui de. O Brasil pela imagem: a ilustração de livros e o passado colonial. In: SERRA, Elizabeth. (Org.). A Arte de Ilustrar Livros para Crianças e Jovens no Brasil. Fundação Nacional do Livro Infantil e Juvenil. Rio de Janeiro: FNLIJ, 2013.

OLIVEIRA, Rui de. Pelos Jardins Boboli: Reflexões sobre a arte de ilustrar para crianças e jovens. Rio de Janeiro: Nova Fronteira, 2008.

POWERS, Alan. Era uma vez uma capa: história ilustrada da literatura infantil. São Paulo: Cosac Naify, 2008.

REYES, Yolanda. Onde vivem os monstros: bons livros para crianças nem sempre boas. Revista Emília e Jornal El Tiempo, maio. 2012.

TATAR, Maria. Contos de fadas: edição comentada e ilustrada. Trad. Maria Luiza X. de A. Borges. Rio de janeiro: Jorge Zahar Ed., 2004.

ZILBERMAN, Regina. A literatura infantil na escola. São Paulo: Global, 2003. 
O LIVRO ILUSTRADO DE LITERATURA INFANTIL NO BRASIL: HISTÓRIAS, CONCEPÇÕES E...

\section{Sobre a autora}

Andrea Rodrigues Dalcin é graduada em Pedagogia (Faculdade de Educação Padre Anchieta), Mestre em Educação (UNICAMP) e Doutora em Educação (UNICAMP). Atuou como Formadora de Professores e Gestores e, atualmente, está como Diretora de Escola na Prefeitura Municipal de Cajamar/SP.

E-mail: deiadalcin@uol.com.br. 